\title{
Can Factor V Leiden and prothrombin G20210A testing in women with recurrent pregnancy loss result in improved pregnancy outcomes?: Results from a targeted evidence-based review
}

\author{
Linda A. Bradley, PhD ${ }^{1}$, Glenn E. Palomaki, PhD'1, Jessica Bienstock, MD, $\mathrm{MPH}^{2}$, \\ Elizabeth Varga, $\mathrm{MS}^{3,4}$ and Joan A. Scott, MS ${ }^{5,6}$
}

\begin{abstract}
Women with recurrent pregnancy loss are offered Factor V Leiden (F5) and/or prothrombin G20210A (F2) testing to identify candidates for anticoagulation to improve outcomes. A systematic literature review was performed to estimate test performance, effect sizes, and treatment effectiveness. Electronic searches were performed through April 2011, with review of references from included articles. English-language studies addressed analytic validity, clinical validity, and/or clinical utility and satisfied predefined inclusion criteria. Adequate evidence showed high analytic sensitivity and specificity for F5 and F2 testing. Evidence for clinical validity was adequate. The summary odds ratio for association of recurrent pregnancy loss with F5 in case-controlled studies was 2.02 (95\% confidence interval, 1.60-2.55), with moderate heterogeneity and suggestion of publication bias. Longitudinal studies in women with
\end{abstract}

recurrent pregnancy loss or unselected cohorts showed F5 carriers were more likely to have a subsequent loss than noncarriers (odds ratios: 1.93 and 2.03, respectively). Results for F2 testing were similar. For clinical utility, evidence was adequate that anticoagulation treatments were ineffective (except in antiphospholipid antibody syndrome) and had treatment-associated harms. The certainty of evidence is moderate (high, moderate, and low) that anticoagulation of women with recurrent pregnancy loss and F5/F2 variants would currently lead to net harms.

Genet Med 2012:14(1):39-50

Key Words: F2 G20210A; F5 G1691A; Factor V Leiden; habitual abortion; prothrombin; recurrent pregnancy loss; systematic review; thrombophilia
Pregnancy loss is a common medical problem among reproductive age women. ${ }^{1}$ However, relatively few women having one pregnancy loss experience multiple or "recurrent" pregnancy losses (RPLs). Approximately $5 \%$ of such women experience a second pregnancy loss and only $1-2 \%$ three or more. ${ }^{1}$ Evaluation for RPL often includes ruling out parental chromosome abnormalities, identifying maternal exposures, and testing for underlying maternal conditions. ${ }^{1,2}$ Effective clinical interventions are available for some etiologies, such as correcting uterine anomalies surgically and treating antiphospholipid syndrome with aspirin and heparin..$^{3-5}$

The evidence review summarized herein addressed the association of inherited thrombophilia with RPL, focusing on tests for two genetic variants that are frequently ordered: Factor $\mathrm{V}$ Leiden (“F5") and prothrombin G20210A ("F2"). F5 defines a single-nucleotide substitution in the $F 5$ gene (i.e., Factor $\mathrm{V}$ Leiden; F5 c.1691G>A; and p.Arg506Gln), ${ }^{3,6}$ whereas F2 defines a single-nucleotide substitution in an untranslated region of the F2 gene (i.e., prothrombin G20210A and F2 c.20210G >A)., 4,6
Associations between these (and other) heritable thrombophilia variants and serious pregnancy complications (e.g., RPL, fetal growth restriction, placental abruption, and preeclampsia) began to appear in the literature in $1996 .{ }^{6}$ By 2005 , laboratories were offering clinical testing for F5/F2 as part of "infertility" or RPL evaluations. ${ }^{7}$ In some states, these tests continue to be available directly to consumers through the internet, without involvement of healthcare providers. The F5/F2 variants are the most common genetic variants associated with venous thromboembolism (VTE) ${ }^{3,4}$ Five to $7 \%$ of individuals of northern European white ancestry worldwide are F5 carriers (heterozygotes). ${ }^{8}$ In the United States, $5.1 \%$ of non-Hispanic whites, $2 \%$ of Hispanic/Mexican Americans, and 1.2\% of African Americans are F5 carriers. ${ }^{9}$ F2 carriers are found in $2.2 \%$ of US non-Hispanic whites and Hispanic/Mexican Americans and in $0.6 \%$ of African Americans. ${ }^{9}$ The F5 variant is virtually absent in native Asian and African populations, and F2 is rare. ${ }^{8,10}$ Individuals having two copies of the $F 5$ or $F 2$ variants (approximately 1 in 1,000 and $<1$ in 8,000 whites, respectively), 
or one of each variant, are much less common. ${ }^{9}$ A thrombotic pathogenesis for pregnancy loss proposes that one or two copies of these variants could enhance the existing hypercoagulable state in pregnant women and that impaired fetal circulation or thrombotic vasculopathy in the placenta could result in placenta-mediated pregnancy complications and fetal loss. ${ }^{3,4,11,12}$

$F 5$ and $F 2$ are the most frequently ordered genetic variants associated with RPL ${ }^{13,14}$ but does the accumulated knowledge base support the broad-based use of these tests to screen women with RPL to identify those who may benefit from specific management or treatment? This review addresses the overarching question (Table 1): "Does testing reproductive age women with recurrent pregnancy loss (RPL) for Factor $V$ Leiden (F5 c.1691G >A) and prothrombin (F2 c.20210 G>A) variants improve outcomes, or are testing results useful in medical and personal decision-making?" If no studies directly answer the overarching question, a chain of evidence will be attempted, as shown in the analytic framework (Figure 1). This review does not address: testing other markers associated with thrombophilia (e.g., MTHFR, proteins $\mathrm{C}$ and S); testing for other adverse pregnancy outcomes (e.g., growth restriction, placental abruption, and preeclampsia); or testing women with a personal history of thrombotic events.

\section{MATERIALS AND METHODS}

To guide the review, an analytic framework (Figure 1) and key questions (Table 1) were refined in consultation with a Technical Expert Panel (see Acknowledgments). Standard methods for evaluating analytic validity, clinical validity, and clinical utility included systematic searches of the published and gray literature (e.g., technology and policy reports and white papers not published in peer-reviewed journals), use of preset inclusion and exclusion criteria (eTable 1, Supplementary Data online), data abstraction and analyses, and grading of individual studies and overall strength of evidence. ${ }^{15-17}$ Electronic searches were conducted in PubMed, HuGE Navigator (version 2.0), ${ }^{18}$ and the Cochrane Library, using MeSH terms (e.g., "abortion, habitual," "Factor V," "factor V Leiden," and "prothrombin"), key words from identified articles (e.g., F5/G1691A/factor V Leiden and RPL, recurrent miscarriage, stillbirth, and intrauterine fetal demise), and other related terms (e.g., genetic association and genetic testing). Initial searches included the time period January 1, 1990, to March 31, 2010; an update of the literature search on clinical validity and utility was conducted through April 30, 2011. Bibliographies were hand searched and information sought through targeted gray literature searches. One team member (L.A.B.) reviewed articles for inclusion and abstracted raw data into electronic spreadsheets; another (G.E.P.) reviewed the articles and spreadsheets to validate eligibility and the accuracy of data abstraction. Discrepancies were resolved by discussion.

For this review, analytic validity is defined as the test's ability to accurately and reliably identify the variant or genotype of interest in specimens consistent with those to be tested in clinical practice. ${ }^{15,16}$ Included articles would provide sufficient data to evaluate assay performance characteristics (e.g., repeatability of test results) and robustness (i.e., resistance to small changes in preanalytic and analytic variables) and to compute estimates of analytic sensitivity and specificity with $95 \%$ confidence intervals (CIs) ${ }^{15,16}$ Clinical validity is defined as the ability of the test to accurately and reliably identify or predict the disorder (or condition, phenotype) of interest. ${ }^{15,16}$ Included articles for clinical validity would assess the strength of association between test results and the disorder of interest and/or provide data from which to compute performance estimates (e.g., clinical sensitivity/specificity, odds ratio [OR], and relative risk). Data could be derived from published meta-analyses and/or analysis of primary reports of studies that met a minimum case definition for RPL ( $\geq 2$ losses in the first or second trimester, or $\geq 1$ stillbirth or intrauterine fetal demise in the third trimester); described selection criteria for cases and controls; performed $F 5$ and/or F2 testing on all women; and provided sufficient raw data to compute effect sizes with $95 \%$ CIs.

Clinical utility is defined as evidence of measurable improvement in health outcomes, and/or the test's added value to management or treatment decisions compared with current management without the testing. ${ }^{15,16}$ Included articles for clinical utility would address the benefits and harms related to F5/F2 testing among women diagnosed with RPL, such as treatments for women with RPL, trials assessing improved outcomes based on treatments, and evidence that decision-making processes or clinical outcomes are impacted by testing and/or the setting in which testing occurs (e.g., test ordered by a physician and direct-to-consumer purchase).

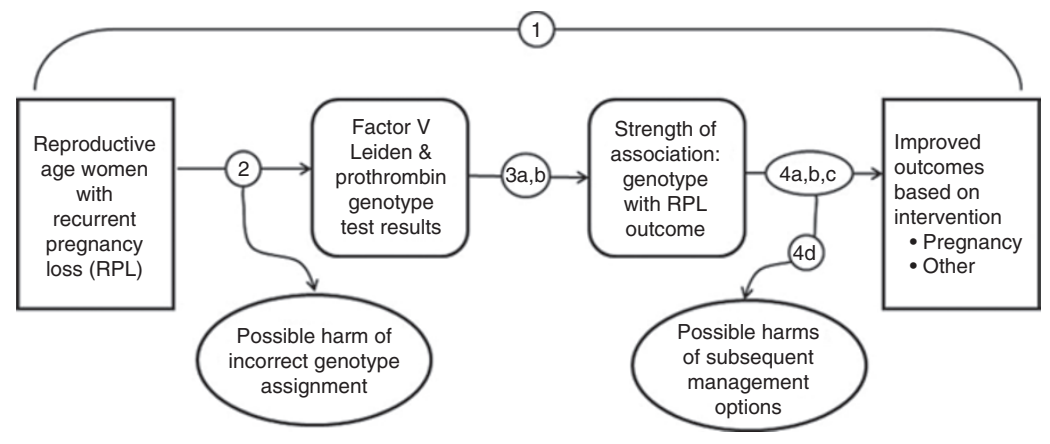

Figure 1 Analytic framework: Factor V Leiden G1691A and prothrombin G20210A testing in women with recurrent pregnancy loss. This schematic shows the analytic framework underlying the current review. The numbers indicate the four key questions in Table 1. 
Table 1 Key questions (KQ)

\begin{tabular}{|c|c|}
\hline KQ 1 & $\begin{array}{l}\text { Overarching question: Does testing reproductive age women with recurrent pregnancy loss (RPL) for F5 c. } 1691 \mathrm{G}>\mathrm{A} \text { and } F 2 \\
\text { c. } 20210 \mathrm{G}>\mathrm{A} \text { variants improve pregnancy outcomes, or are testing results useful in medical or personal decision making? }\end{array}$ \\
\hline KQ 2 & $\begin{array}{l}\text { Analytic validity: What is the analytic validity of tests that identify } F 5 \text { c. } 1691 \mathrm{G}>\mathrm{A} \text { and } F 2 \text { c.20210G }>A \text { variants, including the analytic } \\
\text { sensitivity and specificity, reproducibility, assay robustness (e.g., failure rates and resistance to changes in variables such as sample } \\
\text { quality), and other factors? }\end{array}$ \\
\hline \multirow[t]{2}{*}{ KQ 3} & $\begin{array}{l}\text { Clinical validity: What is the clinical validity of tests that identify F5 c. } 1691 \mathrm{G}>A \text { and } F 2 \text { c.20210G >A variants, including clinical } \\
\text { sensitivity and specificity and positive and negative predictive values? }\end{array}$ \\
\hline & $\begin{array}{l}\text { B. Do other factors (e.g., race/ethnicity, family history, and medical history) affect the strength of association between RPL and the } \\
\text { presence of } F 5 \text { c. } 1691 \mathrm{G}>A \text { and } F 2 \text { c.20210G }>A \text { variants? }\end{array}$ \\
\hline \multirow[t]{3}{*}{ KQ 4} & $\begin{array}{l}\text { Clinical utility: What is the balance of benefits and harms associated with testing in women with RPL for F5 c. } 1691 \mathrm{G}>\mathrm{A} \text { and F2 } \\
\text { c. } 20210 \mathrm{G}>\mathrm{A} \text { variants in practice? }\end{array}$ \\
\hline & A. What are the treatment options for women with RPL who have identified F5 c. $1691 \mathrm{G}>\mathrm{A}$ and $F 2$ c.20210G>A variants? \\
\hline & $\begin{array}{l}\text { D. What are potential harms associated with testing women with RPL for } F 5 \text { c. } 1691 \mathrm{G}>\mathrm{A} \text { and } F 2 \mathrm{c.} 20210 \mathrm{G}>\mathrm{A} \text { variants and } \\
\text { subsequent management options (e.g., genotyping error or misinterpretation of results leading to excessive or inadequate } \\
\text { treatment)? }\end{array}$ \\
\hline
\end{tabular}

Because of the low prevalence of the homozygous F5/F2 genotypes (1 per 1000 or less), homozygotes and heterozygotes were grouped together (dominant model). Performance estimates and summary ORs with corresponding 95\% CIs were derived and summarized using random effects modeling weighted by each data set's total variance (Comprehensive Meta-analysis, version 2, Biostat, Englewood NJ). ${ }^{19}$ Between- study heterogeneity was evaluated using the $Q$ test and $I^{2}$ statistic. ${ }^{19,20}$ Potential for publication bias was assessed using a funnel plot and the Egger regression test. ${ }^{19,21}$ For each case-control study, the observed genotype frequencies in cases and controls were compared with expected frequencies based on Hardy-Weinberg equilibrium ( $\chi 2$ test with 1 degree of freedom). All $P$ values are two sided at the $P=0.05$ level.

Before abstraction of clinical validity data, potential covariates were identified for stratified analyses should heterogeneity be identified. These covariates included method of testing (activated protein $C$ resistance (APCR) and genotyping), publication year (effects of decreased APCR prescreening and/or improving test performance after 2002), study size, race/ethnicity of subjects, site of the study, number of losses $(\geq 2$ and $\geq 3$ ), timing of losses (trimester), pattern of losses (primary, secondary), stated exclusion based on a personal history of VTE, and the extent to which the etiology of RPL was "unexplained" (reporting on the clinical evaluation to identify other causes). Data sources and study designs (Levels 1-4), quality of individual studies (good, fair, and marginal), and overall quality of evidence for analytic validity and clinical utility (convincing, adequate, or inadequate) were graded using a published methodology $y^{16}$ that is consistent with other approaches. ${ }^{22-24}$ The case-control and cohort studies reviewed for clinical validity were graded using the same method, ${ }^{16}$ with additional criteria based on the STROBE checklist. ${ }^{25}$

\section{RESULTS}

Figure 2 provides a summary of the literature review. Abstracts were reviewed for 754 unique citations identified through electronic searches; articles were obtained for 261, and 41 others were identified through hand searches. Of 302 articles reviewed, 174 did not satisfy inclusion criteria, and 116 met the initial overall and key question-specific inclusion criteria.

\section{Analytic validity}

Six published articles ${ }^{6,26-30}$ and seven gray literature documents $^{31-37}$ addressed Key Question 2. In the United States, F5/F2 testing is widely offered in a variety of laboratory settings (e.g., national, hospital, and genetic specialty) using US Food and Drug Administration cleared tests or laboratory developed tests. ${ }^{6,26,37}$ Five US Food and Drug Administration 510(k) Summary Documents provided information on assay performance characteristics (e.g., reproducibility and robustness) and reported high concordance between index and referent (bidirectional sequencing) test results. ${ }^{32-36} \mathrm{~A}$ published systematic review of 41 F5 and 23 F2 method comparison studies also found high (99\%) concordance between index and referent tests. ${ }^{26,37}$ Limitations of the latter method comparisons included referent methods that did not include either a "gold standard " (bidirectional sequencing) or test samples with genotype confirmed by broad consensus. Only 11 studies (27\%) reported blinding samples, ${ }^{26}$ and none provided estimates of analytic sensitivity or specificity under "real world" conditions. 


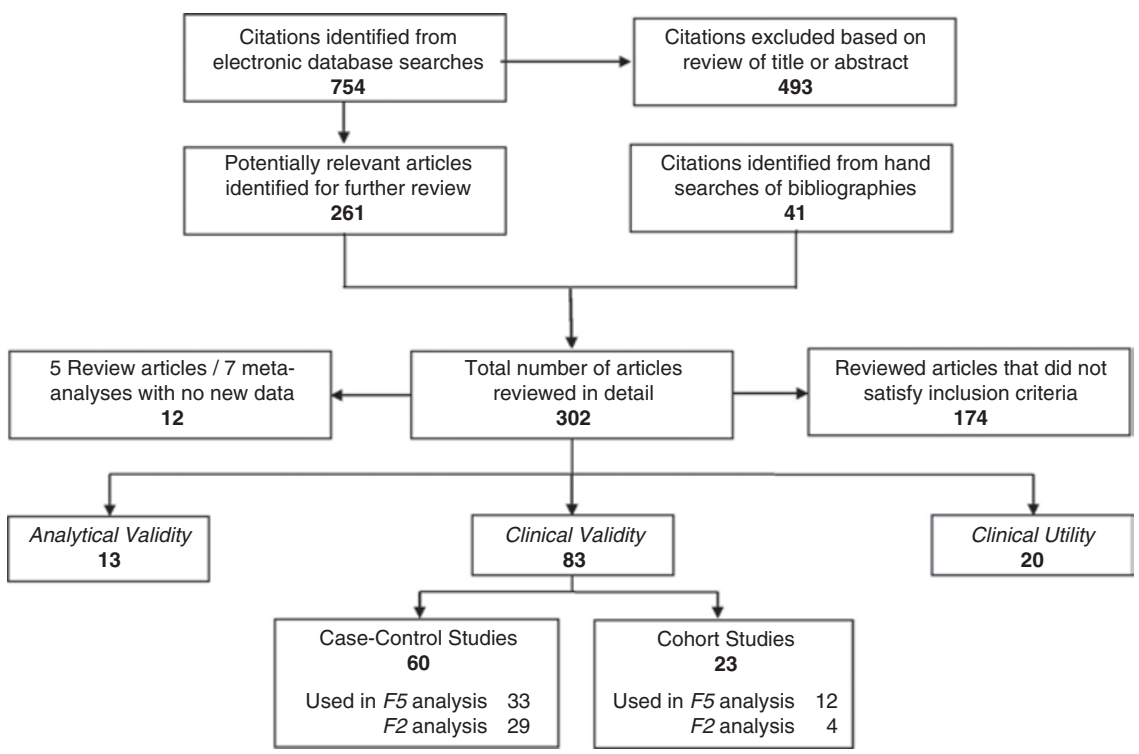

Figure 2 Overview of literature search and selection of key question-specific articles.

Two small, one-time interlaboratory comparison studies ${ }^{29,30}$ (Level 2, grade Fair) ${ }^{16}$ were excluded from computation of performance estimates due to concerns about generalizability (e.g., variation in sample types and protocols). However, experienced external proficiency testing programs for F5/F2 are available in the United States, ${ }^{31}$ United Kingdom/Europe, ${ }^{28}$ and Australasia. ${ }^{27}$ Three proficiency testing data sets from two sources had sufficient raw data for analysis of error rates (i.e., false positives and false negatives). ${ }^{27,31}$ Summary estimates of analytic sensitivity and specificity were $98.8 \%$ and $99.3 \%$ for F5 tests, respectively; results for $F 2$ were $98.3 \%$ and $99.6 \%$, respectively (Table 2). Heterogeneity was high for $F 5\left(I^{2}>70 \%, P<0.05\right)$, possibly due an observed small proportion of poorly performing laboratories. ${ }^{27}$ Heterogeneity was low for $F 2\left(I^{2} \leq 20 \%, P \geq 0.30\right)$. These data sources were graded Level 1 (highest), quality Good ${ }^{27}$ and Fair ${ }^{31}$ (i.e., met quality standards but not published). ${ }^{16}$

\section{Summary}

The evidence on analytic validity is adequate (scale inadequate, adequate, and convincing) ${ }^{16}$ to reliably estimate the analytic sensitivity and specificity and reproducibility of F5/F2 test results. The rating was not convincing because results were not stratified by analytic method/platform, and data were collected between 1998 and 2003. These factors may limit generalizability to current testing methods and laboratories.

\section{Clinical validity}

Five reviews ${ }^{38-42}$ provided historical perspective on $\mathrm{F5/}$ F2 testing and RPL, and seven meta-analyses addressed case-control ${ }^{43-48}$ and cohort $^{49}$ studies. No meta-analysis included recent studies, matched our inclusion criteria, and adequately addressed our key questions (Table 1). Consequently, data from primary studies of different designs were

Table 2 Estimates of analytic validity for the $F 5$ and $F 2$ variants

Analytic performance of $F 5$ testing

Analytic performance of $F 2$ testing

\begin{tabular}{|c|c|c|c|c|}
\hline $\begin{array}{l}\text { Program information } \\
\text { (years included) }\end{array}$ & $\begin{array}{l}\text { Sensitivity }(95 \% \mathrm{Cl}) \\
\text { (errors/total) }\end{array}$ & $\begin{array}{l}\text { Specificity }(95 \% \mathrm{Cl}) \\
\text { (errors/total) }\end{array}$ & $\begin{array}{l}\text { Sensitivity }(95 \% \mathrm{Cl}) \\
\text { (errors/total) }\end{array}$ & $\begin{array}{l}\text { Specificity }(95 \% \mathrm{Cl}) \\
\text { (errors/total) }\end{array}$ \\
\hline \multirow{2}{*}{$\begin{array}{l}\text { The United States, CAP/ACMG }{ }^{31} \\
\text { (1999-2003) }\end{array}$} & $99.3 \%(98.9-99.6)$ & $99.3 \%(98.6-99.7)$ & $98.4 \%(97.3-99.0)$ & $99.7 \%(99.2-99.9)$ \\
\hline & $(14 / 2117)$ & $(9 / 1220)$ & $(16 / 976)$ & $(5 / 1532)$ \\
\hline \multirow[t]{2}{*}{ UK/Europe, NEQAS 28 (1999-2002) } & $98.5 \%(97.6-99.2)$ & $99.7 \%(99.1-99.9)$ & $99.1 \%(97.9-99.6)$ & $99.7 \%(98.9-99.9)$ \\
\hline & $(15 / 1022)$ & $(2 / 766)$ & $(6 / 645)$ & $(2 / 730)$ \\
\hline Australasia, RCPA ${ }^{27}$ (1998-2003) & $98.1 \%(97.1-98.8)$ & $98.4 \%(97.1-99.3)$ & $98.0 \%(96.3-98.9)$ & $99.4 \%(98.6-99.8)$ \\
\hline \multirow[t]{2}{*}{ Summary estimate } & $98.8 \%(97.7-99.3)$ & $99.3 \%(98.2-99.7)$ & $98.3 \%(97.7-98.9)$ & $99.6 \%(99.3-99.8)$ \\
\hline & $(49 / 4185)$ & $(21 / 2625)$ & $(33 / 2157)$ & $(12 / 3145)$ \\
\hline Heterogeneity & $I^{2}=79 \%, P=0.01$ & $I^{2}=72 \%, P=0.03$ & $I^{2}=20 \%, P=0.30$ & $I^{2}=0 \%, P=0.60$ \\
\hline
\end{tabular}

CAP/ACMG, College of American Pathologists/American College of Medical Genetics; Cl, confidence interval; NEQAS, National External Quality Assessment Scheme; RCPA, Royal College of Pathologists Australasia. 
analyzed to estimate effect sizes. Case-control studies were used to investigate an association between the presence of F5 or F2 variants and RPL. Cohort studies addressed two different questions, the subsequent recurrence of pregnancy loss in women with RPL and the occurrence of pregnancy loss in unselected cohorts of women (e.g., primigravidas combined with varied pregnancy histories, and diverse race/ethnicity).

\section{Case-control studies}

Of 73 identified case-control studies, 60 met initial criteria. ${ }^{50-109}$ Fifteen studies were excluded based on reported consanguinity in cases, ${ }^{51,65}$ overlap of data with another included study $y^{83,104,109}$ or inabilitytocomputeORs(i.e.,noobserved carriersincasesand/or controls). ${ }^{53,55,56,59,60,67,74,84,94,107}$ All but three of the 45 remaining studies satisfied Hardy-Weinberg criteria ( $\chi 2$; test; $P \geq 0.05$ ); these three were excluded. ${ }^{77,103,108}$ Of interest, two of these studies ${ }^{77,108}$ were in a small subset of studies conducted in nonEuropean white populations. Using a random effects model, the summary OR for 42 studies was 2.34 (95\% CI: 1.88-2.92; $P<0.001)$, with moderate heterogeneity $\left(I^{2}=45 \% ; P<0.001\right)$. To explore this heterogeneity, results were stratified by the preselected covariates.

Of the 10 covariates examined, only two were found to be associated with significant differences. Among five studies (conducted in Israel, ${ }^{95,100,110}$ Serbia, ${ }^{80}$ and Spain ${ }^{54}$ ), a phenotypic test, APCR, was used to determine which women would be tested for the F5 variant. The remaining 37 studies genotyped all women. The ORs in these two groups differed significantly (OR of 4.35 and 2.19 in the five and 37 studies, respectively; $P=0.008)$. The five studies did not technically meet the inclusion criterion of genotyping all patients, and the ability of the functional APCR test to accurately and reliably identify the presence of $F 5$ has changed over time. Thus, these five studies were excluded from further analysis. Another group of four studies from India, ${ }^{102}$ Palestine, ${ }^{71}$ Lebanon/Bahrain, ${ }^{62}$ and Egypt ${ }^{81}$ was compared with the 33 studies that reported on mainly white populations of northern European/Jewish ancestry. The OR in the first group was higher (ORs of 3.94 and 2.02, respectively; $P=0.11$ ). Had the two Tunisian studies ${ }^{77,108}$ been included, the difference would have been statistically significant (ORs of 4.35 and 2.02, respectively; $P=0.005)$. Differences may have resulted from relatively high $\left(15 \%^{62}\right.$ and $\left.11 \%^{71}\right)$ or low $\left(1 \%^{102}\right)$ observed carrier rates, failure to satisfy Hardy-Weinberg criteria, ${ }^{77,108}$ and other variables (e.g., methodological differences, ascertainment, and other biases).

The most relevant summary OR $(2.02,95 \%$ CI: $1.60-2.55$; $P<0.001)$ was derived from the 33 case-control studies that focused on white populations of northern European/Jewish ancestry. Heterogeneity remained moderate $\left(I^{2}=39 \%\right.$, $P=0.012$ ). Figure 3 presents a Forest plot of these data. Reanalyses of the selected covariates in this subset identified no significant effects. The funnel plot ${ }^{19,111}$ was highly asymmetric with 10 studies imputed with low ORs (Egger regression test $\left.{ }^{19,21} P=0.058\right)$.
Of 38 identified case-control studies on the association of F2 and RPL, 36 met initial inclusion criteria. ${ }^{50,52,55,57-59,61,63,65,68,69,72,73,75 \text {, }}$ 76,78,80,82,83,86-89,91,92,96-99,101,102,104,105,112-114 Seven studies were excluded based on overlap of data with another included study $y^{83,104}$ or inability to compute ORs. ${ }^{55,59,65,102,114}$ One study did not initially satisfy Hardy-Weinberg criteria $(P=<0.001) .{ }^{105}$ When a likely typographical error was corrected, the criteria were easily met, and the study was included with the correction. The summary OR for the remaining 29 studies was 2.07 (95\% CI: $1.59-2.70 ; P<0.001)$, with low heterogeneity $(I 2=0 \%$; $P=0.84$ ). Figure 4 presents a Forest plot of these data. The funnel plot ${ }^{19,111}$ was slightly asymmetric with three studies imputed with low ORs (Egger regression test ${ }^{19,21} P=0.45$ ).

Overall, the included studies were Level 3 (lower quality case-control studies). ${ }^{16}$ Most studies were rated Fair, but 10 had one or more poor elements and were graded Marginal. ${ }^{50,55,62,64,73,77,79,81,112,113}$

\section{Cohort studies}

The overarching question in this review addresses how to inform F5/F2 carrier women with RPL about their recurrence risk for pregnancy loss and provide access to an effective treatment. From this perspective, an ideal study would identify a representative cohort of women with "unexplained " RPL (i.e., other strong causal factors excluded) for which there is access to data on test results, clinical evaluation, treatments, and subsequent pregnancy outcomes. After genotyping, fetal loss rates in one or more subsequent pregnancy(ies) would be compared between F5/F2 carrier and noncarrier women. Of 23 identified cohort studies, only four met this initial inclusion criterion that study subjects meet the definition of RPL. ${ }^{115-118}$

Two studies prospectively followed pregnant white women with a history of $\geq 3$ pregnancy losses occurring at $\leq 12$ weeks' gestation $^{116,118}$ and a third ${ }^{117}$ reviewed pregnancy outcomes in a retrospective cohort of women having $\geq 3$ pregnancy losses at $\leq 13$ weeks. All showed an effect on loss rates in carrier women with RPL, and two individually reached significance (Table 3). A fourth study retrospectively ascertained pregnancy histories for a cohort of primigravid women followed longitudinally as part of a large multicenter study on thrombosis (first-degree relatives of patients with VTE but no personal VTE events). ${ }^{115}$ Table 3 lists the data from third pregnancies of women with two previous losses. This study represents a high-risk scenario, with a higher rate of women with two variants included among "carriers" (7.4\% versus an expected 1-2\%). However, no significant effect on loss rate was observed. The summary OR for $F 5$ carriers with RPL to have a subsequent event was 1.93 (95\% CI: 1.21-3.09, $P=0.006$; eFigure 1, Supplementary Data online), with low heterogeneity $(I 2=0 \%, P=0.42)$ (Table 3$)$. Only one of these studies ${ }^{117}$ reported on F2 (OR: 3.29, $P=0.17$; eFigure 2, Supplementary Data online). Overall, these studies were considered to be Level 2 and rated Good ${ }^{116-118}$ to Fair ${ }^{115}$ (based on lack of power).

Twenty cohort studies reported on fetal loss rates in unselected populations, stratified by genotype. Ten were excluded based on design or execution issues (see eTable 2, Supplementary 


\begin{tabular}{|c|c|c|c|c|c|c|c|c|}
\hline \multirow[b]{2}{*}{ Author } & \multirow[b]{2}{*}{ Year } & \multirow[b]{2}{*}{ OR } & \multirow[b]{2}{*}{$(95 \% \mathrm{Cl})$} & \multirow[b]{2}{*}{$p$} & \multicolumn{2}{|c|}{ RPL } & \multicolumn{2}{|c|}{ Control } \\
\hline & & & & & F5 & All & F5 & All \\
\hline Wramsby ${ }^{105}$ & 2000 & 7.23 & $(1.53-34.0)$ & .012 & 11 & 62 & 2 & 69 \\
\hline Subrt ${ }^{99}$ & 2008 & 6.48 & (1.88-22.3) & .003 & 18 & 206 & 3 & 206 \\
\hline Foka ${ }^{63}$ & 2000 & 5.54 & $(1.76-17.4)$ & .003 & 15 & 80 & 4 & 100 \\
\hline Onderoglu ${ }^{86}$ & 2006 & 5.39 & $(2.24-13.0)$ & $<.001$ & 29 & 102 & 7 & 102 \\
\hline Grandone ${ }^{66}$ & 1997 & 4.39 & $(1.31-14.7)$ & .016 & 7 & 43 & 5 & 118 \\
\hline Brenner ${ }^{57}$ & 1999 & 3.99 & $(1.81-8.78)$ & .001 & 24 & 76 & 11 & 106 \\
\hline Krause $^{75}$ & 2005 & 3.96 & $(1.64-9.56)$ & .002 & 24 & 133 & 7 & 133 \\
\hline Fatini ${ }^{61}$ & 2000 & 3.85 & $(0.75-19.8)$ & .11 & 6 & 59 & 2 & 70 \\
\hline Raziel ${ }^{91}$ & 2001 & 3.80 & $(0.71-20.2)$ & .12 & 6 & 36 & 2 & 40 \\
\hline Agorastos $^{50}$ & 2002 & 3.43 & $(0.4-34.9)$ & .30 & 1 & 8 & 4 & 100 \\
\hline Glueck $^{64}$ & 2008 & 3.23 & $(1.47-7.13)$ & .004 & 9 & 44 & 47 & 638 \\
\hline Sottilotta ${ }^{97}$ & 2006 & 3.00 & $(0.91-9.85)$ & .070 & 5 & 55 & 7 & 217 \\
\hline Hohlagschwandtner ${ }^{69}$ & 2003 & 2.80 & $(0.90-8.69)$ & .075 & 15 & 145 & 4 & 101 \\
\hline Reznikoff-Etievant ${ }^{92}$ & 2001 & 2.41 & $(1.17-4.98)$ & .02 & 27 & 260 & 11 & 240 \\
\hline Souza ${ }^{98}$ & 1999 & 2.33 & $(0.27-20.1)$ & .44 & 1 & 28 & 6 & 384 \\
\hline Ridker $^{93}$ & 1998 & 2.28 & $(0.98-5.30)$ & .056 & 9 & 113 & 16 & 437 \\
\hline Hopmeier ${ }^{70}$ & 2008 & 2.15 & $(0.60-7.67)$ & .24 & 8 & 49 & 4 & 48 \\
\hline Many $^{78}$ & 2002 & 2.08 & $(0.40-10.8)$ & .38 & 3 & 40 & 3 & 80 \\
\hline Murphy ${ }^{85}$ & 2000 & 2.08 & $(0.45-9.54)$ & .35 & 2 & 41 & 13 & 540 \\
\hline Ivanov 72 & 2009 & 2.00 & $(0.81-4.92)$ & .13 & 20 & 153 & 7 & 100 \\
\hline Sotiriadis $^{96}$ & 2007 & 1.76 & $(0.41-7.55)$ & .45 & 5 & 99 & 3 & 102 \\
\hline Metz $^{79}$ & 1997 & 1.75 & $(0.42-7.20)$ & .44 & 6 & 100 & 3 & 85 \\
\hline Pauer ${ }^{88}$ & 2003 & 1.69 & $(0.68-4.20)$ & .26 & 12 & 101 & 9 & 122 \\
\hline Pasquier & 2008 & 1.16 & $(0.60-2.24)$ & .65 & 15 & 311 & 25 & 599 \\
\hline Toth $^{101}$ & 2008 & 1.14 & $(0.50-2.58)$ & .76 & 13 & 151 & 12 & 157 \\
\hline Altintas ${ }^{52}$ & 2007 & 1.13 & $(0.47-2.75)$ & .78 & 9 & 114 & 13 & 185 \\
\hline Hefler ${ }^{68}$ & 2004 & 1.12 & $(0.43-2.91)$ & .81 & 10 & 94 & 9 & 94 \\
\hline Kutteh $^{76}$ & 1999 & 1.09 & $(0.09-12.7)$ & .94 & 1 & 23 & 2 & 50 \\
\hline Jaslow $^{73}$ & 2010 & 0.99 & $(0.54-1.80)$ & .97 & 21 & 311 & 25 & 366 \\
\hline Mougiou $^{82}$ & 2008 & 0.97 & $(0.35-2.74)$ & .96 & 8 & 212 & 7 & 181 \\
\hline Pihusch $^{89}$ & 2001 & 0.91 & $(0.35-2.37)$ & .86 & 8 & 101 & 11 & 128 \\
\hline $\mathrm{Rai}^{90}$ & 2001 & 0.82 & $(0.43-1.55)$ & .54 & 74 & 1111 & 12 & 150 \\
\hline Carp 58 & 2002 & 0.59 & $(0.15-2.28)$ & .45 & 4 & 108 & 5 & 82 \\
\hline Consensus & (REM) & 2.02 & $(1.60-2.55)$ & $<.001$ & 426 & 4569 & 301 & 6130 \\
\hline
\end{tabular}

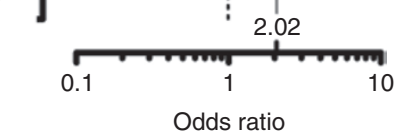

Figure 3 Forest plot of the association of $\mathbf{F 5}$ genotype and recurrent pregnancy loss (RPL) in $\mathbf{3 3}$ case-control studies. Studies are ordered by effect size. The summary OR is 2.02 with moderate heterogeneity $\left(I^{2}=39 \%, P=0.012\right)$. Cl, confidence interval; OR, odds ratio.

Data online). Eight studies ${ }^{85,115,119-124}$ were analyzed to provide information about the occurrence rate of pregnancy losses among F5 carriers. The summary OR was 2.03 (95\% CI: 1.293.17; $P=0.002$; eFigure 1, Supplementary Data online), with high heterogeneity $\left(I^{2}=66 \% ; P=0.004\right)$. Four studies ${ }^{121,123-125}$ in unselected cohorts provided information about the occurrence rate of pregnancy losses among F2 carriers (eFigure 2, Supplementary Data online). The summary F2 OR was 1.77 (95\% CI: $0.87-3.61 ; P=0.11)$, with high heterogeneity $\left(I^{2}=\right.$ $62 \% ; P=0.049)$. Three cohort studies ${ }^{85,115,123}$ were rated Level 2, Good; all others were rated Level 3, Fair. ${ }^{120-122,124-126}$

\section{Summary}

These case-control and cohort studies reflect methodological diversity and clinical heterogeneity. Studies have been conducted in more than 20 countries, using different study designs and in routine care settings and high-risk referral centers. Study limitations have included inadequately described and/or heterogeneous case and control groups and cohorts, insufficient information to adequately assess potential biases, and missing or incomplete information on important covariates such as maternal age and number and timing of losses and small studies (30\% of F5 and $86 \%$ of F2 studies reported on fewer than 10 carriers among women with RPL).

The rationale for offering F5/F2 testing in clinical practice has been largely based on small case-control studies reporting higher odds that women with RPL will carry F5/F2 variants than women without RPL. These data confirmed an effect for both F5 and F2 $(P<0.001)$. More importantly, there was concern that the case-control data did not provide direct evidence 


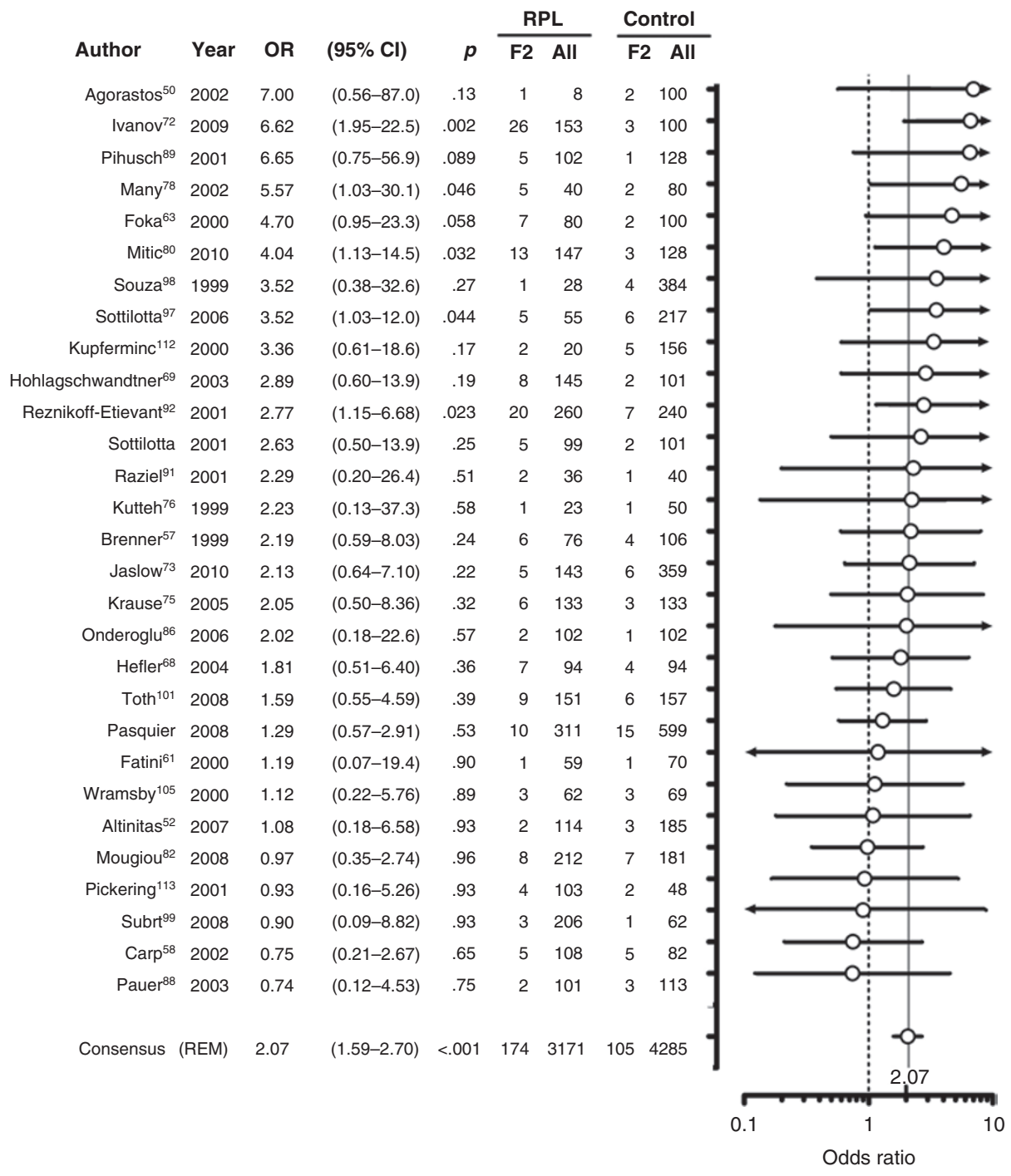

Figure 4 Forest plot of the association of $\mathbf{F} 2$ genotype and recurrent pregnancy loss (RPL) in $\mathbf{2 9}$ case-control studies. Studies are ordered by effect size. The summary OR is 2.07 with low heterogeneity $\left(I^{2}=0 \%, P=0.84\right)$.

on the risk for subsequent losses among carrier women with RPL. However, results from the case-control studies, as well as the cohort studies addressing occurrence of pregnancy loss and recurrence of loss in carrier women, are consistent. In summary, the evidence is adequate (scale inadequate, adequate, and convincing) to establish clinical validity of $F 5$ and $F 2$ testing in this scenario. The evidence for $F 5$ is not convincing due to high heterogeneity and the potential for publication bias to reduce the effect size. The evidence for F2 is not convincing due to insufficient data (i.e., a single cohort study in women with RPL that showed an effect but did not reach significance).

\section{Clinical utility}

A test is said to have clinical utility, when results change clinical management, health outcomes improve, and the benefits outweigh known or potential harms. ${ }^{15,16}$ In women with RPL, the most likely outcome in the next pregnancy is a normal birth. Pregnancy loss rates vary from 10 to $50 \%$ based on multiple factors. ${ }^{127-129}$ Therefore, high-quality evidence is needed to show that a proposed intervention will improve the likelihood of a successful pregnancy in women with RPL who carry one or two F5/F2 variants. No studies were identified that directly addressed the balance of benefits and harms related to F5/F2 testing in this clinical scenario or the impact on decision making for either direct-to-consumer testing or testing ordered by a healthcare provider (overarching question, Key Question 4C). Treatments proposed for women with RPL, regardless of F5/ F2 status (Key Question 4A), currently include low-dose aspirin, unfractionated or low molecular weight heparin (LMWH), and combined anticoagulant treatments. ${ }^{12,119,129-136}$ Two randomized controlled trials recently reported from the Netherlands ${ }^{133}$ and Scotland ${ }^{119}$ found that loss rates in women with RPL did not differ significantly among three study groups: low-dose aspirin only; LMWH plus low-dose aspirin; and placebo ${ }^{133}$ or 
Table 3 Summary of observed pregnancy loss rates in cohort studies of women with RPL, stratified by F5/F2 carrier status Number and timing of prior

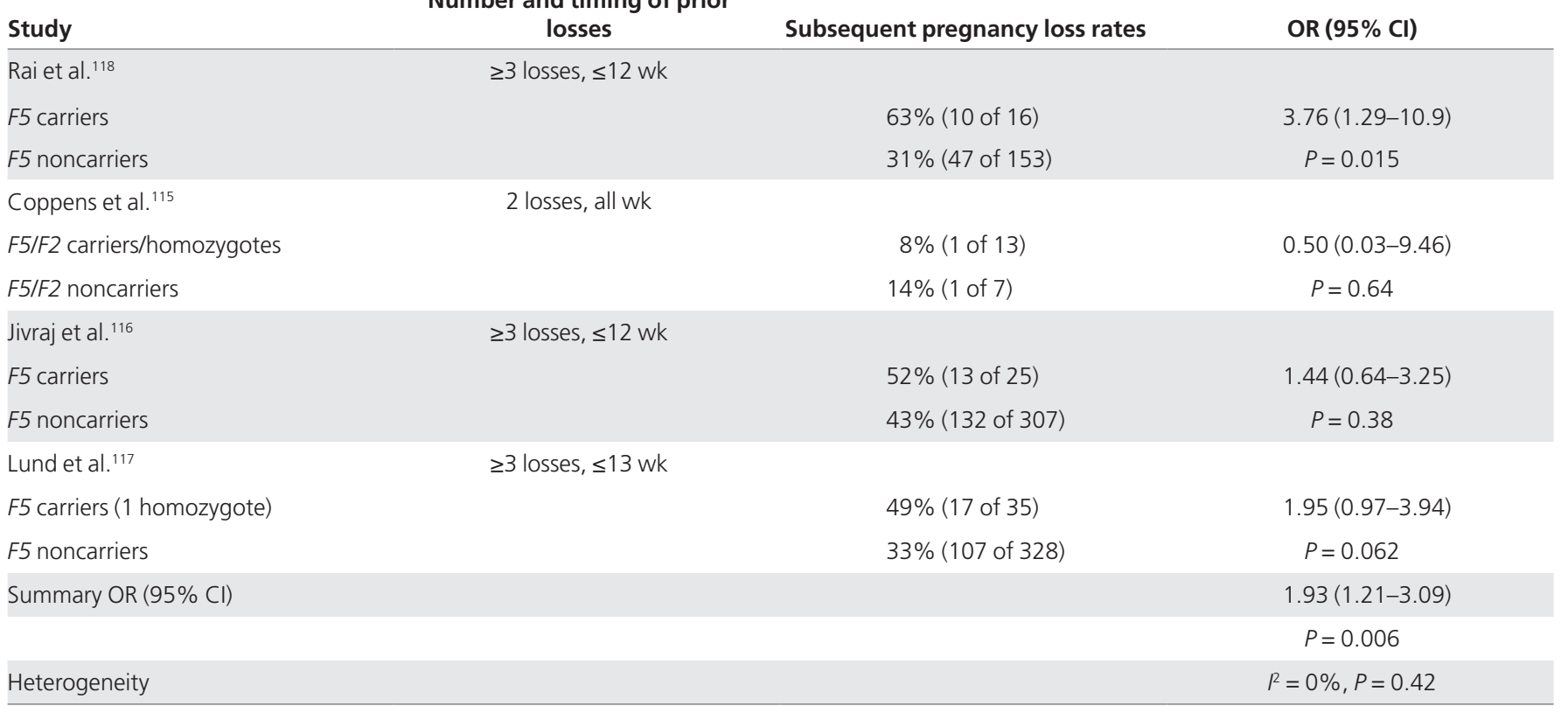

intense surveillance. ${ }^{119}$ Three meta-analyses ${ }^{129,135,136}$ also reported that there is insufficient evidence that these treatments reduce loss rates in women with RPL who do not have antiphospholipid syndrome or support the routine use of these treatments in women with RPL. Other non-health-related benefits of F5/ F2 testing have been proposed, including value of information (i.e., identifying a "cause" for the RPL or allowing for alternative reproductive options), ${ }^{137}$ but no relevant studies were identified. F5/F2 testing has also been suggested to have benefit in identifying risk for VTE in pregnant women without a personal history, but evidence of efficacy and cost-effectiveness is lacking. ${ }^{12,138}$

Potential and observed harms associated with testing women with RPL for F5/F2 and subsequent treatment options have been reported. Unfractionated heparin and LMWH do not cross the placenta, removing much of the risk to the fetus. ${ }^{12,129}$ For carrier women, proposed treatment during pregnancy presents measurable risks. Although rare, anticoagulantrelated maternal risks can be serious and include bleeding (e.g., injection site bruising, nosebleeds, and hemorrhage/vaginal bleeding), osteopenia, thrombocytopenia, and allergic skin reactions. ${ }^{119,129,131,138} \mathrm{LMWH}$ is associated with a lower risk for heparin-induced thrombocytopenia and osteopenia ${ }^{129,138}$ but significantly increases the cost of care. ${ }^{12,47}$ Other drawbacks include discomfort from daily injections and inconvenience. ${ }^{12,47}$ A potential harm of testing is a false-positive result, possibly leading to unneeded treatment. Information is not available on potential psychosocial and ethical harms (e.g., acceptability and impact of testing, implications of results for family members, and societal cost).

In summary, the evidence is adequate to support the lack of safe and effective treatments that will lead to a reduction in future pregnancy loss among women with RPL. ${ }^{47,119,129,133,135,136}$ The RCTs have generally been underpowered for women with
F5/F2-related RPL, and, therefore, the evidence is inadequate on the efficacy of these treatments in this subgroup. Given the lack of benefit, and the potential harms, F5/F2 testing and treatment in women with RPL is likely to be associated with a net harm. The certainty of evidence was rated as moderate. The certainty was not high because limitations in data quantity, quality, consistency, and generalizability reduce confidence, and new evidence could alter the conclusion. ${ }^{16}$

\section{DISCUSSION}

Genetic and epidemiologic research suggests that RPL of maternal etiology is multifactorial, with risk determined by interactions of multiple genetic variants and environmental factors. Factors implicated in RPL recurrence risk include maternal age, race/ethnicity, number of previous miscarriages, and whether care is received early in pregnancy. ${ }^{127,128}$ The F5 and F2 variants have a low prevalence in the population, and women with these variants can have normal pregnancies, so have relatively small impact on the absolute risk for pregnancy loss. It is not surprising, therefore, that designing and conducting studies to measure the relatively small effects associated with these specific variants has proved challenging. Methodological problems in case-control and cohort studies on F5/F2 and RPL are described herein and in previous reviews ${ }^{44,46-48}$ and include variable case definitions and quality of diagnosis for RPL, ascertainment bias in obtaining cases/controls and cohorts, lack of power, poorly described and/or heterogeneous patient and control populations, and lack of information to assess bias and confounding variables.

Most analyses have been conducted in whites of northern European and Jewish ancestry. As our preliminary data suggest, results in Asian and Middle Eastern populations may differ in prevalence of at risk genotypes, effect size, or both. 
Kist et al. ${ }^{48}$ previously reported APCR pretesting and ethnicity (Israeli whites) as "confounders" (heterogeneity and significance not reported). However, APCR was used in four of the nine Israeli studies in that analysis, and we did not observe a difference between Jewish Israeli women and other whites of northern European ancestry. Most studies provide insufficient information to accurately assess maternal age or the number and timing of pregnancy losses as covariates. Data from the first trimester are particularly problematic, as few studies differentiate between very early anembryonic losses and postembryonic losses, and this may impact effect size. ${ }^{72}$ This and other meta-analyses have been unable to find significant differences in F5 or F2 ORs based on trimester or number of losses. ${ }^{43,45,46,59}$ Results from a recent meta-analysis ${ }^{49}$ of unselected cohort studies reported a lower effect size (F5 OR: 1.52; F2 OR: 1.13) but were generally consistent with our findings (ORs 2.03 and 1.68, respectively) on fetal loss occurrence rates in carrier women.

In summary, the data support an association between F5/F2 carrier status and pregnancy loss. However, important gaps in knowledge remain.

- What information can be provided to women with RPL and a positive genotype about their risk for loss in subsequent pregnancies? Well-designed and adequately powered studies are needed in women with RPL to estimate the clinical sensitivity and specificity of F5/F2 testing for subsequent pregnancy loss, with stratification by important covariates (e.g., race/ethnicity, maternal age, gestational age, and number of losses).

- Is there a safe and effective intervention that can be offered to women at risk that will increase the likelihood of a successful pregnancy? Regardless of F5/F2 genotype, there is no evidence for an effective intervention for women with RPL. Studies are needed to demonstrate a safe and effective treatment for women with RPL who carry a F5/F2 variant(s).

- Information is also needed on the current utilization of tests, impact of positive test results on physician and/or patient/ consumer decision making, and perception of risk related to treatment versus routine supportive care. Of concern are preliminary clinical surveys reporting that thrombophilia panels are ordered in as many as three quarters of pregnant women with RPL ${ }^{13,14}$ and that management is commonly modified in women who test positive. ${ }^{13,14,139,140}$ From a practitioner's perspective, patients who have experienced RPL are more likely to request treatment, once found to have a genetic "abnormality" that could potentially explain the losses. The risks associated with treatment may be readily accepted without full consideration by patients desperate for a successful pregnancy. F5/F2 testing is also available direct to consumers, exposing an unknown number of women to potential harms.

\section{SUPPLEMENTARY MATERIAL}

Supplementary material is linked to the online version of the paper at http://www.nature.com/gim

\section{ACKNOWLEDGMENTS}

This work was supported by the Genetics and Public Policy Center through a contract (Subaward No. 2000694007) from a Pew Charitable Trusts primary award (No. 2008-01005). The authors acknowledge members of the Technical Evaluation Panel (TEP) from The Genetics and Public Policy Center for their input and review of the initial evidence report: Kathy Hudson, PhD (currently at the National Institutes of Health) and Sara Katsanis, MS (currently at the Duke Institute for Genome Sciences \& Policy, Duke University). They thank Dr. James Haddow, Women \& Infants Hospital of Rhode Island, and David Kaufman, The Genetics and Public Policy Center, for editorial and content review of the manuscript, and Joanne Beaudoin for general support and obtaining and cataloguing reference materials.

Author contributions: Dr. Bradley had full access to all the data in the study and takes responsibility for the integrity of the data and the accuracy of the data analysis. Study concept and design: Bradley, Palomaki, Bienstock, Scott, and Varga. Acquisition of data: Bradley and Palomaki. Analysis and interpretation of data: Bradley and Palomaki. Drafting of the manuscript: Bradley and Palomaki. Critical revision of the manuscript for important intellectual content: Bradley, Palomaki, Bienstock, Scott, and Varga. Statistical analysis: Bradley and Palomaki. Obtained funding: Bradley. Administrative, technical, or material support: Bradley and Palomaki. Study supervision: Bradley.

Role of the Sponsor: In addition to providing support for Dr. Bradley and Dr. Palomaki, the Genetics and Public Policy Center participated in developing the concept and design of the original systematic evidence review and in critical revision of this subsequent manuscript for important intellectual content. They had no role in the conduct of the original systematic review and subsequent update, in collection, management, analysis, and interpretation of the data, or in preparation of the original evidence report.

The findings and conclusions in this report are those of the authors and do not necessarily represent those of the Genetics and Public Policy Center or The Pew Charitable Trusts.

\section{DISCLOSURE}

The authors declare no conflict of interest.

\section{REFERENCES}

1. Christiansen OB, Steffensen R, Nielsen HS, Varming K. Multifactorial etiology of recurrent miscarriage and its scientific and clinical implications. Gynecol Obstet Invest 2008;66:257-267.

2. Warren JE, Silver RM. Genetics of pregnancy loss. Clin Obstet Gynecol 2008;51:84-95.

3. Kujovich JL. Factor V Leiden thrombophilia. GENEReviews, 1999. http://www ncbi.nlm.nih.gov/bookshelf/br.fcgi?book_gene\&part_factor-v-leiden. Accessed 3 June 2009.

4. Kujovich JL. Prothrombin thrombophilia. GENEReviews, 2006. http://www.ncbi. nlm.nih.gov/bookshelf/br.fcgi?book_gene\&part_ptt. Accessed 3 June 2009.

5. Empson M, Lassere M, Craig J, Scott J. Prevention of recurrent miscarriage for women with antiphospholipid antibody or lupus anticoagulant. Cochrane Database Syst Rev 2005:CD002859.

6. Cooper PC, Rezende SM. An overview of methods for detection of factor $V$ Leiden and the prothrombin G20210A mutations. Int J Lab Hematol 2007;29:153-162.

7. Phelan R (CEO, DNA Direct). Genetics and public policy center genetics perspectives on policy seminar, direct-to-consumer genetic testing: medicine in 
the marketplace. National Press Club: Washington, DC, 2005. http://www. dnapolicy.org/news.past.php?action_detail\& past_event_id_18. Accessed 27 July 2010.

8. Rees DC, Cox M, Clegg JB. World distribution of factor V Leiden. Lancet 1995;346:1133-1134.

9. Chang MH, Lindegren ML, Butler MA, et al. Prevalence in the United States of selected candidate gene variants: Third National Health and Nutrition Examination Survey, 1991-1994. Am J Epidemio/ 2009;169:54-66.

10. Lucotte G, Mercier G. Population genetics of factor V Leiden in Europe. Blood Cells Mol Dis 2001;27:362-367.

11. Kutteh WH, Triplett DA. Thrombophilias and recurrent pregnancy loss. Semin Reprod Med 2006;24:54-66.

12. Bates SM, Greer IA, Pabinger I, Sofaer S, Hirsh J. Venous thromboembolism, thrombophilia, antithrombotic therapy, and pregnancy: American College of Chest Physicians Evidence-Based Clinical Practice Guidelines (8th Edition). Chest 2008;133(6 Suppl):844S-886S.

13. Norrie G, Farquharson RG, Greaves M. Screening and treatment for heritable thrombophilia in pregnancy failure: inconsistencies among UK early pregnancy units. Br J Haematol 2009;144:241-244.

14. Cleary-Goldman J, Bettes B, Robinson JN, Norwitz E, Schulkin J. Thrombophilia and the obstetric patient. Obstet Gynecol 2007;110:669-674.

15. Haddow JE, Palomaki GE. ACCE: a model process for evaluating data on emerging genetic tests. In: Khoury M, Little J, Burke W (eds). Human Genome Epidemiology: A Scientific Foundation for Using Genetic Information to Improve Health and Prevent Disease. Oxford University Press: Oxford, UK, 2003:217-233.

16. Teutsch SM, Bradley LA, Palomaki GE, et al. The Evaluation of Genomic Applications in Practice and Prevention (EGAPP) Initiative: methods of the EGAPP Working Group. Genet Med 2009;11:3-14.

17. Sagoo GS, Little J, Higgins JP. Systematic reviews of genetic association studies. Human Genome Epidemiology Network. PLoS Med 2009;6:e28.

18. Yu W, Gwinn M, Clyne M, Yesupriya A, Khoury MJ. A navigator for human genome epidemiology. Nat Genet 2008;40:124-125.

19. Borenstein M, Hedges L, Higgins JPT, Rothstein HR. Introduction to MetaAnalysis. Wiley: West Sussex, UK, 2009.

20. Higgins JP, Thompson SG, Deeks JJ, Altman DG. Measuring inconsistency in meta-analyses. BMJ 2003;327:557-560.

21. Egger M, Davey Smith G, Schneider M, Minder C. Bias in meta-analysis detected by a simple, graphical test. BMJ 1997;315:629-634.

22. Guyatt GH, Oxman AD, Vist GE, et al.; GRADE Working Group. GRADE: an emerging consensus on rating quality of evidence and strength of recommendations. BMJ 2008;336:924-926

23. Liberati A, Altman DG, Tetzlaff J, et al. The PRISMA statement for reporting systematic reviews and meta-analyses of studies that evaluate health care interventions: explanation and elaboration. Ann Intern Med 2009;151:W65-W94.

24. Little J, Higgins JP, loannidis JP, et al. STrengthening the REporting of Genetic Association studies (STREGA): an extension of the STROBE Statement. Ann Intern Med 2009:150:206-215.

25. Vandenbroucke JP, von Elm E, Altman DG, et al.; STROBE initiative. Strengthening the Reporting of Observational Studies in Epidemiology (STROBE): explanation and elaboration. Ann Intern Med 2007;147:W163-W194.

26. Emadi A, Crim MT, Brotman DJ, et al. Analytic validity of genetic tests to identify factor V Leiden and prothrombin G20210A. Am J Hematol 2010;85:264-270.

27. Hertzberg M, Neville $S$, Favaloro E, McDonald D. External quality assurance of DNA testing for thrombophilia mutations. Am J Clin Pathol 2005;123: 189-193.

28. Jennings I, Kitchen S, Woods TA, Preston FE. Multilaboratory testing in thrombophilia through the United Kingdom National External Quality Assessment Scheme (Blood Coagulation) Quality Assurance Program. Semin Thromb Hemost 2005;31:66-72.

29. Márki-Zay J, Klein CL, Gancberg D, Schimmel HG, Dux L. European external quality control study on the competence of laboratories to recognize rare sequence variants resulting in unusual genotyping results. Clin Chem 2009:55:739-747.

30. Tripodi A, Chantarangkul V, Menegatti M, Tagliabue L, Peyvandi F. Performance of clinical laboratories for DNA analyses to detect thrombophilia mutations. Clin Chem 2005;51:1310-1311.

31. ACCE Review: Venous Thromboembolism, 2004. ACCE model system for collecting, analyzing and disseminating information on genetic tests. http://www. cdc.gov/genomics/gtesting/ACCE/fbr.htm. Accessed 20 July 2009.

32. K033612: 510(k) Substantial Equivalence Determination Decision Summary, Factor II (Prothrombin) G20210A (LightCycler), Roche Diagnostics Corp., 2003.
United States Food and Drug Administartion (FDA) Releasable 510(k) Database. http://www.accessdata.fda.gov/cdrh_docs/pdf3/K033612.pdf. Accessed 9 June 2009.

33. K060564: 510. (k) Summary for (INFINITITM F5/F2/MTHFR), Auto- Genomics Inc., 2007. US FDA Releasable 510. (k) Database. http://www.accessdata.fda.gov/ cdrh_docs/pdf6/K060564.pdf. Accessed 9 June 2009.

34. K070597: 510(k) Summary (Verigene_System F5/F2/MTHFR), Nanosphere Inc. 2007. US FDA Releasable 510(k) Database. http://www.accessdata.fda.gov/ cdrh docs/pdf7/K070597.pdf. Accessed 9 June 2009.

35. K082118: 510. (k) Summary (Xpert_HemosIL_Factor II \& Factor V), Cepheid Inc., 2009. US FDA Releasable 510. (k) Database. http://www.accessdata.fda. gov/cdrh_docs/pdf7/K070597.pdf. Accessed 17 June 2010.

36. K093974: 510(k) Summary (eSensor_Factor II-Factor V-MTHFR), Osmetech Molecular Diagnostics, 2010. US FDA Releasable 510(k) Database. http://www.accessdata.fda.gov/cdrh_docs/pdf9/ K093974.pdf. Accessed 17 June 2010.

37. Segal JB, Brotman DJ, Emadi A, et al. Outcomes of genetic testing in adults with a history of venous thromboembolism. Evidence Report/Technology Assessment No. 180 (Prepared by Johns Hopkins University Evidence Based Practice Center under contract no. HHSA 290-2007-10061-1). AHRQ Publication No. 09-E011, 2009. Rockville, MD: Agency for Healthcare Research and Quality.

38. Krabbendam I, Franx A, Bots ML, Fijnheer R, Bruinse HW. Thrombophilias and recurrent pregnancy loss: a critical appraisal of the literature. Eur J Obstet Gynecol Reprod Biol 2005;118:143-153.

39. Jordaan DJ, Schoon MG, Badenhorst PN. Thrombophilia screening in pregnancy. Obstet Gynecol Surv 2005;60:394-404.

40. Ghee CB, Burrows RF. Prothrombin G20210A mutation is not associated with recurrent miscarriages. Aust NZ J Obstet Gynaecol 2002;42:167-169.

41. Cleary-Goldman J, Nakhuda GS, Zimmermann RC, Sauer MV. The role of factor $V$ Leiden mutation in recurrent pregnancy loss. J Am Med Womens Assoc 2003:58:165-172.

42. Calderwood CJ, Greer IA. The role of factor V Leiden in maternal health and the outcome of pregnancy. Curr Drug Targets 2005;6:567-576.

43. Rey E, Kahn SR, David M, Shrier I. Thrombophilic disorders and fetal loss: a meta-analysis. Lancet 2003:361:901-908.

44. Dudding TE, Attia J. The association between adverse pregnancy outcomes and maternal factor $\mathrm{V}$ Leiden genotype: a meta-analysis. Thromb Haemost 2004:91:700-711.

45. Kovalevsky G, Gracia CR, Berlin JA, Sammel MD, Barnhart KT. Evaluation of the association between hereditary thrombophilias and recurrent pregnancy loss: a meta-analysis. Arch Intern Med 2004;164:558-563.

46. Robertson L, Wu O, Langhorne P, et al.; Thrombosis: Risk and Economic Assessment of Thrombophilia Screening (TREATS) Study. Thrombophilia in pregnancy: a systematic review. Br J Haematol 2006;132:171-196.

47. Wu O, Robertson L, Twaddle S, et al. Screening for thrombophilia in high-risk situations: systematic review and cost-effectiveness analysis. The Thrombosis: Risk and Economic Assessment of Thrombophilia Screening (TREATS) study. Health Technol Assess 2006;10:1-110.

48. Kist WJ, Janssen NG, Kalk JJ, Hague WM, Dekker GA, de Vries JI. Thrombophilias and adverse pregnancy outcome - A confounded problem! Thromb Haemost 2008:99:77-85.

49. Rodger MA, Betancourt MT, Clark $P$, et al. The association of factor $V$ leiden and prothrombin gene mutation and placenta-mediated pregnancy complications: a systematic review and meta-analysis of prospective cohort studies. PLOS Med 2010:7:e1000292.

50. Agorastos T, Karavida A, Lambropoulos A, et al. Factor V Leiden and prothrombin G20210A mutations in pregnancies with adverse outcome. J Matern Fetal Neonatal Med 2002;12:267-273.

51. Aksoy M, Tek I, Karabulut H, Berker B, Soylemez F. The role of thrombofilia related to Factor V Leiden and Factor II G20210A mutations in recurrent abortions. J Pak Med Assoc 2005:55:104-108.

52. Altintas A, Pasa S, Akdeniz N, et al. Factor $V$ Leiden and G20210A prothrombin mutations in patients with recurrent pregnancy loss: data from the southeast of Turkey. Ann Hemato/ 2007;86:727-731.

53. Ayadurai T, Muniandy S, Omar SZ. Thrombophilia investigation in Malaysian women with recurrent pregnancy loss. J Obstet Gynaecol Res 2009;35: 1061-1068.

54. Balasch J, Reverter JC, Fábregues F, et al. First-trimester repeated abortion is not associated with activated protein C resistance. Hum Reprod 1997;12: 1094-1097.

55. Behjati R, Modarressi MH, Jeddi-Tehrani M, et al. Thrombophilic mutations in Iranian patients with infertility and recurrent spontaneous abortion. Ann Hematol 2006;85:268-271. 
56. Biswas A, Choudhry P, Mittal A, et al. Recurrent abortions in Asian Indians: no role of factor $V$ Leiden Hong Kong/Cambridge mutation and MTHFR polymorphism. Clin Appl Thromb Hemost 2008;14:102-104.

57. Brenner B, Sarig G, Weiner Z, Younis J, Blumenfeld Z, Lanir N. Thrombophilic polymorphisms are common in women with fetal loss without apparent cause. Thromb Haemost 1999;82:6-9.

58. Carp H, Salomon O, Seidman D, et al. Prevalence of genetic markers for thrombophilia in recurrent pregnancy loss. Hum Reprod 2002;17:1633-1637.

59. Coulam CB, Jeyendran RS, Fishel LA, Roussev R. Multiple thrombophilic gene mutations rather than specific gene mutations are risk factors for recurrent miscarriage. Am J Reprod Immuno/ 2006;55:360-368.

60. Dizon-Townson DS, Kinney S, Branch DW, Ward K. The factor V Leiden mutation is not a common cause of recurrent miscarriage. J Reprod Immunol 1997;34:217-223.

61. Fatini C, Gensini F, Battaglini B, et al. Angiotensin-converting enzyme DD genotype, angiotensin type 1 receptor $C$ genotype, and hyperhomocysteinemia increase first-trimester fetal-loss susceptibility. Blood Coagul Fibrinolysis 2000;11: 657-662.

62. Finan RR, Tamim H, Ameen G, Sharida HE, Rashid M, Almawi WY. Prevalence of factor V G1691A (factor V-Leiden) and prothrombin G20210A gene mutations in a recurrent miscarriage population. Am J Hematol 2002;71: 300-305

63. Foka ZJ, Lambropoulos $A F$, Saravelos $H$, et al. Factor $V$ leiden and prothrombin G20210A mutations, but not methylenetetrahydrofolate reductase $6677 \mathrm{~T}$, are associated with recurrent miscarriages. Hum Reprod 2000;15:458-462.

64. Glueck CJ, Gogenini S, Munjal J, Tracy T, Pranikoff J, Wang P. Factor V Leiden mutation: a treatable etiology for sporadic and recurrent pregnancy loss. Fertil Steril 2008;89:410-416.

65. Gonen R, Lavi N, Attias D, et al. Absence of association of inherited thrombophilia with unexplained third-trimester intrauterine fetal death. Am J Obstet Gynecol 2005;192:742-746.

66. Grandone $\mathrm{E}$, Margaglione M, Colaizzo D, et al. Factor V Leiden is associated with repeated and recurrent unexplained fetal losses. Thromb Haemost 1997:77:822-824.

67. Hashimoto K, Shizusawa Y, Shimoya K, et al. The factor V Leiden mutation in Japanese couples with recurrent spontaneous abortion. Hum Reprod 1999;14:1872-1874.

68. Hefler L, Jirecek S, Heim K, et al. Genetic polymorphisms associated with thrombophilia and vascular disease in women with unexplained late intrauterine fetal death: a multicenter study. J Soc Gynecol Investig 2004;11:42-44.

69. Hohlagschwandtner M, Unfried G, Heinze G, Huber JC, Nagele F, Tempfer C. Combined thrombophilic polymorphisms in women with idiopathic recurrent miscarriage. Fertil Steril 2003;79:1141-1148.

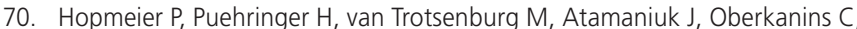
Dossenbach-Glaninger A. Association of endothelial protein $C$ receptor haplotypes, factor $V$ Leiden and recurrent first trimester pregnancy loss. Clin Biochem 2008:41:1022-1024

71. Hussein AS, Darwish H, Shelbayeh K. Association between factor V Leiden mutation and poor pregnancy outcomes among Palestinian women. Thromb Res 2010;126:e78-e82.

72. Ivanov PD, Komsa-Penkova RS, Konova El, Kovacheva KS, Simeonova MN, Popov JD. Association of inherited thrombophilia with embryonic and postembryonic recurrent pregnancy loss. Blood Coagul Fibrinolysis 2009;20:134-140.

73. Jaslow CR, Carney JL, Kutteh WH. Diagnostic factors identified in 1020 women with two versus three or more recurrent pregnancy losses. Fertil Steril 2010:93:1234-1243.

74. Kobashi G, Kato EH, Morikawa M, et al. MTHFR C677T Polymorphism and factor $V$ Leiden mutation are not associated with recurrent spontaneous abortion of unexplained etiology in Japanese women. Semin Thromb Hemost 2005:31:266-271.

75. Krause M, Sonntag B, Klamroth R, et al. Lipoprotein (a) and other prothrombotic risk factors in Caucasian women with unexplained recurrent miscarriage. Results of a multicentre case-control study. Thromb Haemost 2005;93:867-871.

76. Kutteh WH, Park VM, Deitcher SR. Hypercoagulable state mutation analysis in white patients with early first-trimester recurrent pregnancy loss. Fertil Steril 1999:71:1048-1053.

77. Mahjoub T, Mtiraoui N, Tamim H, et al. Association between adverse pregnancy outcomes and maternal factor V G1691A (Leiden) and prothrombin G20210A genotypes in women with a history of recurrent idiopathic miscarriages. Am J Hematol 2005;80:12-19.
78. Many A, Elad R, Yaron Y, Eldor A, Lessing JB, Kupferminc MJ. Third-trimester unexplained intrauterine fetal death is associated with inherited thrombophilia. Obstet Gynecol 2002;99(5 Pt 1):684-687.

79. Metz J, Kloss M, O'Malley CJ, et al. Prevalence of factor V Leiden is not increased in women with recurrent miscarriage. Clin Appl Thromb Hemost 1997;3: 137-140.

80. Mitic G, Kovac M, Povazan L, et al. Inherited thrombophilia is associated with pregnancy losses that occur after 12th gestational week in Serbian population. Clin Appl Thromb Hemost 2010;16:435-439.

81. Mohamed MA, El Moaty MA, El Kholy AF, Mohamed SA, Ali Al. Thrombophilic gene mutations in women with repeated spontaneous miscarriage. Genet Test Mol Biomarkers 2010;14:593-597.

82. Mougiou A, Androutsopoulos G, Karakantza M, Theodori E, Decavalas G, Zoumbos N. Inherited thrombophilia screening in Greek women with recurrent fetal loss. Clin Exp Obstet Gynecol 2008;35:172-174.

83. Mtiraoui N, Borgi L, Hizem S, et al. Prevalence of antiphospholipid antibodies, factor V G1691A (Leiden) and prothrombin G20210A mutations in early and late recurrent pregnancy loss. Eur J Obstet Gynecol Reprod Biol 2005:119:164-170.

84. Mukhopadhyay R, Saraswathy KN, Ghosh PK. MTHFR C677T and factor $\checkmark$ Leiden in recurrent pregnancy loss: a study among an endogamous group in North India. Genet Test Mol Biomarkers 2009;13:861-865.

85. Murphy RP, Donoghue C, Nallen RJ, et al. Prospective evaluation of the risk conferred by factor $\mathrm{V}$ Leiden and thermolabile methylenetetrahydrofolate reductase polymorphisms in pregnancy. Arterioscler Thromb Vasc Bio/ 2000;20: 266-270.

86. Onderoglu L, Baykal C, Al RA, Demirtas E, Deren O, Gurgey A. High frequency of thrombophilic disorders in women with recurrent fetal miscarriage. Clin Exp Obstet Gynecol 2006;33:50-54.

87. Pasquier $\mathrm{E}$, Bohec $\mathrm{C}$, Mottier $\mathrm{D}$, et al. Inherited thrombophilias and unexplained pregnancy loss: an incident case-control study. J Thromb Haemost 2009;7: 306-311.

88. Pauer HU, Voigt-Tschirschwitz T, Hinney B, et al. Analyzes of three common thrombophilic gene mutations in German women with recurrent abortions. Acta Obstet Gynecol Scand 2003;82:942-947.

89. Pihusch R, Buchholz T, Lohse $P$, et al. Thrombophilic gene mutations and recurrent spontaneous abortion: prothrombin mutation increases the risk in the first trimester. Am J Reprod Immuno/ 2001:46:124-131.

90. Rai R, Shlebak A, Cohen H, et al. Factor V Leiden and acquired activated protein $C$ resistance among 1000 women with recurrent miscarriage. Hum Reprod 2001;16:961-965.

91. Raziel A, Kornberg Y, Friedler $S$, et al. Hypercoagulable thrombophilic defects and hyperhomocysteinemia in patients with recurrent pregnancy loss. Am Reprod Immunol 2001;45:65-71.

92. Reznikoff-Etiévan MF, Cayol V, Carbonne B, Robert A, Coulet F, Milliez J. Factor $V$ Leiden and G20210A prothrombin mutations are risk factors for very early recurrent miscarriage. BJOG 2001;108:1251-1254

93. Ridker PM, Miletich JP, Buring JE, et al. Factor V Leiden mutation as a risk factor for recurrent pregnancy loss. Ann Intern Med 1998;128(12 Pt 1):1000-1003.

94. Rothbart H, Ohel G, Younis J, Lanir N, Brenner B. High prevalence of activated protein $\mathrm{C}$ resistance due to factor $\mathrm{V}$ leiden mutation in cases of intrauterine fetal death. J Matern Fetal Med 1999:8:228-230.

95. Sarig G, Younis JS, Hoffman R, Lanir N, Blumenfeld Z, Brenner B. Thrombophilia is common in women with idiopathic pregnancy loss and is associated with late pregnancy wastage. Fertil Steril 2002;77:342-347.

96. Sotiriadis A, Vartholomatos G, Pavlou M, et al. Combined thrombophilic mutations in women with unexplained recurrent miscarriage. Am J Reprod Immunol 2007:57:133-141.

97. Sottilotta G, Oriana V, Latella C, et al. Genetic prothrombotic risk factors in women with unexplained pregnancy loss. Thromb Res 2006;117:681-684.

98. Souza SS, Ferriani RA, Pontes AG, Zago MA, Franco RF. Factor V leiden and factor II G20210A mutations in patients with recurrent abortion. Hum Reprod 1999;14:2448-2450.

99. Subrt I, Ulcova-Gallova Z, Bibkova K, et al. Recurrent pregnancy loss and frequency of eight antiphospholipid antibodies and genetic thrombophilic factors in Czech women. Am J Reprod Immuno/ 2008;59:193-200.

100. Tal J, Schliamser LM, Leibovitz Z, Ohel G, Attias D. A possible role for activated protein $\mathrm{C}$ resistance in patients with first and second trimester pregnancy failure. Hum Reprod 1999;14:1624-1627.

101. Toth B, Vocke F, Rogenhofer N, et al. Paternal thrombophilic gene mutations are not associated with recurrent miscarriage. Am J Reprod Immunol 2008:60:325-332. 
102. Vora S, Shetty S, Ghosh K. Thrombophilic dimension of recurrent fetal loss in Indian patients. Blood Coagul Fibrinolysis 2008;19:581-584.

103. Weiner Z, Beck-Fruchter R, Weiss A, Hujirat Y, Shalev E, Shalev SA. Thrombophilia and stillbirth: possible connection by intrauterine growth restriction. BJOG 2004;111:780-783.

104. Wolf $\mathrm{CE}$, Haubelt H, Pauer HU, et al. Recurrent pregnancy loss and its relation to $\mathrm{FV}$ Leiden, Fll G20210A and polymorphisms of plasminogen activator and plasminogen activator inhibitor. Pathophysiol Haemost Thromb 2003;33: 134-137.

105. Wramsby ML, Sten-Linder M, Bremme K. Primary habitual abortions are associated with high frequency of factor V Leiden mutation. Fertil Steril 2000;74: 987-991.

106. Younis JS, Brenner B, Ohel G, Tal J, Lanir N, Ben-Ami M. Activated protein C resistance and factor $V$ Leiden mutation can be associated with first-as well as secondtrimester recurrent pregnancy loss. Am J Reprod Immunol 2000;43: 31-35.

107. Yusoff NM, Abdullah WZ, Ghazali S, et al. The absence of factor $V$ Leiden mutation in Malays with recurrent spontaneous abortions. Aust NZ J Obstet Gynaecol 2002;42:164-166.

108. Zammiti W, Mtiraoui N, Mercier E, et al. Association of factor $V$ gene polymorphisms (Leiden; Cambridge; Hong Kong and HR2 haplotype) with recurrent idiopathic pregnancy loss in Tunisia. A case-control study. Thromb Haemost 2006;95:612-617.

109. Pauer HU, Neesen J, Hinney B. Factor V Leiden and its relevance in patients with recurrent abortions. Am J Obstet Gynecol 1998;178:629.

110. Younis JS, Ohel G, Brenner B, et al. The effect of thrombophylaxis on pregnancy outcome in patients with recurrent pregnancy loss associated with factor $\mathrm{V}$ Leiden mutation. BJOG 2000;107:415-419.

111. Duval S, Tweedie R. Trim and fill: A simple funnel-plot-based method of testing and adjusting for publication bias in meta-analysis. Biometrics 2000;56: 455-463.

112. Kupferminc MJ, Peri H, Zwang E, Yaron Y, Wolman I, Eldor A. High prevalence of the prothrombin gene mutation in women with intrauterine growth retardation, abruptio placentae and second trimester loss. Acta Obstet Gynecol Scand 2000;79:963-967.

113. Pickering W, Marriott K, Regan L. G20210A prothrombin gene mutation: prevalence in a recurrent miscarriage population. Clin Appl Thromb Hemost 2001;7:25-28.

114. Yenicesu Gl, Cetin M, Ozdemir O, et al. A prospective case-control study analyzes 12 thrombophilic gene mutations in Turkish couples with recurrent pregnancy loss. Am J Reprod Immunol 2010;63:126-136.

115. Coppens M, Folkeringa N, Teune MJ, et al. Outcome of the subsequent pregnancy after a first loss in women with the factor $\mathrm{V}$ Leiden or prothrombin 20210A mutations. J Thromb Haemost 2007;5:1444-1448.

116. Jivraj S, Makris M, Saravelos S, Li TC. Pregnancy outcome in women with factor $\checkmark$ Leiden and recurrent miscarriage. BJOG 2009;116:995-998.

117. Lund M, Nielsen HS, Hviid TV, Steffensen R, Nyboe Andersen A, Christiansen OB. Hereditary thrombophilia and recurrent pregnancy loss: a retrospective cohort study of pregnancy outcome and obstetric complications. Hum Reprod 2010;25:2978-2984.

118. Rai R, Backos M, Elgaddal S, Shlebak A, Regan L. Factor V Leiden and recurrent miscarriage-prospective outcome of untreated pregnancies. Hum Reprod 2002:17:442-445.

119. Clark P, Walker ID, Langhorne P, et al.; Scottish Pregnancy Intervention Study (SPIN) collaborators. SPIN (Scottish Pregnancy Intervention) study: a multicenter, randomized controlled trial of low-molecular-weight heparin and low-dose aspirin in women with recurrent miscarriage. Blood 2010;115:4162-4167.

120. Dizon-Townson D, Miller C, Sibai B, et al. The relationship of the factor V Leiden mutation and pregnancy outcomes for mother and fetus. Obstet Gynecol 2005;106:517-524.
121. Karakantza M, Androutsopoulos G, Mougiou A, Sakellaropoulos G, Kourounis G, Decavalas G. Inheritance and perinatal consequences of inherited thrombophilia in Greece. Int J Gynaecol Obstet 2008;100:124-129.

122. Lindqvist PG, Svensson P, Dahlbäck B. Activated protein C resistance-in the absence of factor V Leiden - and pregnancy. J Thromb Haemost 2006;4: 361-366.

123. Lissalde-Lavigne G, Fabbro-Peray P, Cochery-Nouvellon E, et al. Factor V Leiden and prothrombin G20210A polymorphisms as risk factors for miscarriage during a first intended pregnancy: the matched case-control 'NOHA first' study. J Thromb Haemost 2005:3:2178-2184.

124. Said JM, Higgins JR, Moses EK, et al. Inherited thrombophilia polymorphisms and pregnancy outcomes in nulliparous women. Obstet Gynecol 2010;115: 5-13.

125. Silver RM, Zhao Y, Spong CY, et al.; Eunice Kennedy Shriver National Institute of Child Health and Human Development Maternal-Fetal Medicine Units (NICHD MFMU) Network. Prothrombin gene G20210A mutation and obstetric complications. Obstet Gynecol 2010;115:14-20.

126. Clark P, Walker ID, Govan L, Wu O, Greer IA. The GOAL study: a prospective examination of the impact of factor $\mathrm{V}$ Leiden and $\mathrm{ABO}(\mathrm{H})$ blood groups on haemorrhagic and thrombotic pregnancy outcomes. Br J Haematol 2008; $140: 236-240$

127. Brigham SA, Conlon C, Farquharson RG. A longitudinal study of pregnancy outcome following idiopathic recurrent miscarriage. Hum Reprod 1999:14:2868-2871.

128. Clifford K, Rai R, Regan L. Future pregnancy outcome in unexplained recurrent first trimester miscarriage. Hum Reprod 1997;12:387-389.

129. Kaandorp S, Di Nisio M, Goddijn M, Middeldorp S. Aspirin or anticoagulants for treating recurrent miscarriage in women without antiphospholipid syndrome. Cochrane Database Syst Rev 2009:CD004734.

130. Haas DM, Ramsey PS. Progestogen for preventing miscarriage. Cochrane Database Syst Rev 2008:CD003511.

131. Kaandorp SP, Goddijn M, van der Post JA, et al. Aspirin plus heparin or aspirin alone in women with recurrent miscarriage. N Engl J Med 2010;362: 1586-1596.

132. Porter TF, LaCoursiere $Y$, Scott JR. Immunotherapy for recurrent miscarriage. Cochrane Database Syst Rev 2006:CD000112.

133. Kaandorp SP, Goddijn M, van der Post JA, et al. Aspirin plus heparin or aspirin alone in women with recurrent miscarriage. N Engl J Med 2010;362: 1586-1596.

134. Mak A, Cheung MW, Cheak AA, Ho RC. Combination of heparin and aspirin is superior to aspirin alone in enhancing live births in patients with recurrent pregnancy loss and positive anti-phospholipid antibodies: a meta-analysis of randomized controlled trials and meta-regression. Rheumatology (Oxford) 2010;49:281-288.

135. Mantha S, Bauer KA, Zwicker Jl. Low molecular weight heparin to achieve live birth following unexplained pregnancy loss: a systematic review. J Thromb Haemost 2010;8:263-268.

136. Ziakas PD, Pavlou M, Voulgarelis M. Heparin treatment in antiphospholipid syndrome with recurrent pregnancy loss: a systematic review and meta-analysis. Obstet Gynecol 2010;115:1256-1262.

137. Grosse SD, Khoury MJ. What is the clinical utility of genetic testing? Genet Med 2006:8:448-450.

138. Marik PE, Plante LA. Venous thromboembolic disease and pregnancy. N Eng/ J Med 2008:359:2025-2033.

139. Laberge AM, Psaty BM, Hindorff LA, Burke W. Use of Factor V Leiden genetic testing in practice and impact on management. Genet Med 2009;11: 750-756.

140. Bates SM. Consultative hematology: the pregnant patient pregnancy loss. Hematology Am Soc Hematol Educ Program 2010;2010:166-172. 